\title{
Generation of Monoclonal Antibodies to a Human Natural Killer Clone Characterization of Two Natural Killer-associated Antigens, NKH1 $A$ and NKH2, Expressed on Subsets of Large Granular Lymphocytes
}

Thierry Hercend, James D. Griffin, Armand Bensussan, Reinhold E. Schmidt, Mary Ann Edson, Agnes Brennan, Christine Murray, John F. Daley, Stuart F. Schlossman, and Jerome Ritz Division of Tumor Immunology, Dana-Farber Cancer Institute, and the Department of Medicine, Harvard Medical School, Boston, Massachusetts 02115

\begin{abstract}
The initial characterization of two monoclonal antibodies directed at antigens selectively expressed on large granular lymphocytes (LGL) is reported in the present paper. These two reagents, anti-natural killer (NK) $\mathrm{H1}_{\mathrm{A}}$ and anti-NKH2, were obtained following immunization of mouse spleen cells with a cloned human NK cell line termed JT3. In fresh human peripheral blood, both anti-NKH1 ${ }_{A}$ and anti-NKH2 selectively reacted with cells that appeared morphologically as large granular lymphocytes. However, complement lysis studies and two color fluorescence analysis demonstrated that some LGL express both antigens and other cells express only $\mathrm{NKH1}_{\mathrm{A}}$ or NKH2. Functional analysis of these subsets indicated that the population of $\mathrm{NKH1}_{\mathrm{A}^{+}}$cells contains the entire pool of $\mathrm{NK}$ active lymphocytes, whereas expression of NKH2 antigen appeared to delineate a unique subpopulation of LGL which, in a resting state, display a low degree of spontaneous cytotoxicity. Expression of $\mathrm{NKH1}_{A}$ and NKH2 was also investigated using a series of nine well characterized human NK clones. All NK clones were found to be $\mathrm{NKH1}_{\mathrm{A}^{+}}$and four out of nine also expressed NKH2. These results strongly supported the view that $\mathrm{NKH1}_{\mathrm{A}}$ is a "pan-NK" associated antigen, and indicated that at least a fraction of cloned NKH2+ LGL are strongly cytotoxic. Anti-NKH1 was shown to have the same specificity as the previously described N901 antibody and was found here

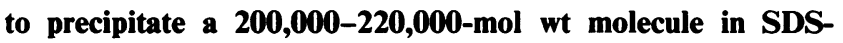
polyacrylamide gel electrophoresis (PAGE) analysis. AntiNKH2 was specific for a structure that migrates at 60,000 mol wt in SDS-PAGE analysis under reducing conditions. Two color immunofluorescence analysis of $\mathrm{NKH1}_{\mathrm{A}}, \mathrm{NKH2}$, and other NK-associated antigens (Leu7 and B73.1) demonstrated variable degrees of coexpression of these antigens, which confirmed that $\mathrm{NKH1}_{\mathrm{A}}$ and $\mathrm{NKH} 2$ define distinct cell surface structures. Anti-NKH1 ${ }_{A}$ and anti-NKH2 appear to be useful reagents for characterizing LGL present in human peripheral blood and for identifying functionally relevant subsets within this heterogeneous population of cytotoxic lymphocytes.
\end{abstract}

Dr. Hercend is a fellow of the Leukemia Society of America. Dr. Ritz is a Scholar of the Leukemia Society of America. Dr. Hercend's present address is Dept. de Biologie Clinique, Institut Gustave Roussy, 94805 Villejuif, France. Address reprint requests to Dr. Ritz.

Received for publication 17 April 1984 and in revised form 24 October 1984.

J. Clin. Invest.

(c) The American Society for Clinical Investigation, Inc.

0021-9738/85/03/932/12 $\$ 1.00$

Volume 75, March 1985, 932-943

\section{Introduction}

Both human and murine studies have previously demonstrated that cells capable of mediating natural killer (NK) ${ }^{1}$ activity are heterogeneous in terms of their cell surface phenotype defined by monoclonal antibodies (1-3). In order to dissect this heterogeneity and study individual NK cells, we have recently developed techniques for generating cloned NK cell lines using lymphocyte-conditioned medium containing interleukin 2 (IL2). This has led to the development of a series of human NK clones that maintained consistent cytotoxic activity and appeared to reflect the diversity of uncultured peripheral blood NK cells $(4,5)$. These NK clones could be classified into three groups by analysis of cell surface markers. One group was shown to be phenotypically similar to mature $\mathrm{T}$ lymphocytes and major histocompatibility complex (MHC) restricted cytotoxic $\mathrm{T}$ cell clones. Cells in this group express $\mathrm{T} 3$ antigen in addition to T8 and T11 antigens and thus appear to have a complete mature $\mathrm{T}$ cell phenotype. Moreover, clones in this group have also been shown to express clonotypic receptor like structures, linked to T3 antigen in an analogous fashion to antigen-specific T cells (6). The second group of NK clones express different combinations of $\mathrm{T}$ lymphocyte-associated surface antigens including $\mathrm{T} 1, \mathrm{~T} 8, \mathrm{~T} 11$, and/or $\mathrm{T} 12$, but lack the mature $T$ cell differentiation antigen, $T 3$. Cells in the third group of NK clones do not express any $T$ cell-associated markers or any other lineage related differentiation antigens. In addition to providing a means for demonstrating the phenotypic heterogeneity of NK cells, characterization of NK clones has also suggested that individual NK cells have different restricted target cell specificities (5).

Although analysis of cloned NK cell lines has provided useful information about NK active lymphocytes at the single cell level, it is also evident that the generation of clones is dependent upon the capacity of individual cells to proliferate in conditioned medium containing IL-2. It is not known at the present time whether all the different types of cells capable of mediating NK activity can respond to IL-2 under these experimental conditions and it is therefore possible that some subsets of NK cells cannot be characterized using this approach.

1. Abbreviations used in this paper: ADDC, antibody-dependent cellular cytotoxicity; AV-PE, avidin-conjugated phycoerythrin; EBV, Epstein Barr virus; F/H, Ficoll-Hypaque; GM-FITC, fluorescein-conjugated goat anti-mouse immunoglobulin; IL-2, interleukin 2; LGL, large granular lymphocytes; LCM, lymphocyte-conditioned medium; MHC, major histocompatibility complex; NK, natural killer; PBL, peripheral blood lymphocytes; PBMC, peripheral blood mononuclear cells; PHA, phytohemagglutinin; SDS-PAGE, SDS-polyacrylamide gel electrophoresis. 
In order to define directly in fresh human peripheral blood both the entire pool of NK active lymphocytes and functional subsets within this fraction, we have also used NK clones for the generation of monoclonal antibodies that would selectively react with these small populations of cells. In the present studies, a previously described human NK clone termed JT3 (5), which has a very common NK phenotype (T3-T4-T8$\mathrm{T} 11+\mathrm{N} 901+$ ), was used as immunogen for production of murine hybridomas. After fusion procedures, the cloned cells were used for identifying monoclonal antibodies with selective reactivity against cells capable of mediating NK activity. This paper reports the initial characterization of two of these reagents, termed anti- $\mathrm{NKH}_{\mathrm{A}}$ and anti-NKH2. Experiments performed here indicate that expression of $\mathrm{NKH}_{\mathrm{A}}$ and $\mathrm{NKH} 2$ molecules defines functionally distinct subsets of large granular lymphocytes (LGL) present in human peripheral blood.

\section{Methods}

Production of the anti-NKH1 and anti-NKH2 monoclonal antibodies. 6-wk-old female Balb/c mice were immunized with JT3 cells. The immunization schedule consisted of an initial intraperitoneal injection of $4 \times 10^{6}$ cells emulsified in complete Freund's adjuvant (Difco Laboratories, Detroit, MI) followed by two weekly intraperitoneal injections of $4 \times 10^{6}$ viable cells in phosphate-buffered saline (PBS). 2 wk later, $2 \times 10^{6}$ cells were injected intravenously, followed by splenectomy $3 \mathrm{~d}$ later. Somatic cell hybridization was carried out by the method of Kohler and Milstein (7).

The initial screening of hybridoma supernatants was carried out as follows: $10,000{ }^{51} \mathrm{Cr}$-labeled JT3 cells were incubated with an aliquot of each hybridoma supernatant for $30 \mathrm{~min}$ at room temperature in $\mathrm{V}$ bottom microtiter plates. Rabbit complement at an appropriate nontoxic dilution (usually $1: 10$ ) was then added for $1 \mathrm{~h}$ at $37^{\circ} \mathrm{C}$. Subsequently, plates were spun down and antibody reactivity was measured as release of ${ }^{51} \mathrm{Cr}$ into the supernatants using a gamma scintillation counter. Positive supernatants were then tested under identical experimental conditions against an autologous $\mathrm{MHC}$ restricted cytotoxic $\mathrm{T}$ cell clone as well as an autologous Epstein Barr virus (EBV) transformed B cell line (Laz 461).

Isolation of subpopulations of peripheral blood cells. Human peripheral blood mononuclear cells (PBMC) were isolated from healthy volunteer donors by Ficoll-Hypaque $(\mathrm{F} / \mathrm{H})$ density gradient centrifugation. Monocyte enriched adherent cells were obtained from PBMC by two step adherence on plastic culture dishes. Granulocytes were isolated from $\mathrm{F} / \mathrm{H}$ gradient pellets using high molecular weight dextran (8). Activated $T$ cells were generated by stimulating $E+$ cells with phytohemagglutinin (PHA) $(2 \mu \mathrm{g} / \mathrm{ml})$ and tested on day 7 after stimulation.

Previously characterized monoclonal antibodies. Several monoclonal antibodies utilized in these studies have been previously described in detail. Anti-T3 defines all mature $\mathrm{T}$ lymphocytes in human peripheral blood (9). T8 antigen is expressed on a subset of peripheral T cells having primarily cytotoxic/suppressor function (10). T4 is expressed on a subset of peripheral $T$ cells having primarily inducer/helper function (11). Anti-T11 defines an antigen associated with the sheep erythrocyte receptor (12). In peripheral blood, N901 antigen is expressed on $\sim 7 \%$ of cells which morphologically appear to be a homogeneous population of LGL. Greater than $95 \%$ of NK activity in peripheral blood is found within the purified $901+$ fraction. Anti-901 antibody does not react with monocytes, granulocytes, B cells, erythrocytes, or platelets (8). The specificity of anti-I2 (anti-Ia) has been previously described in detail (13). Anti-Mo2 defines a 55,000-mol wt molecule selectively expressed on human monocytes (14). Other NK-associated antibodies used in these studies were HNK-1 (15) and B73.1 (16).
B73.1 defines an antigen associated with IgG Fc receptor expressed on some LGL and on granulocytes (17).

Phenotypic analysis of cell surface antigens. Phenotypic analysis was performed by indirect immunofluorescence with fluorescein-conjugated goat anti-mouse Fab IgG (GM-FITC) as described previously (4). Samples were analyzed either on a FACS I (Becton Dickinson \& Co., Mountain View, CA) or an Epics V flow cytometer (Coulter Electronics, Hialeah, FL). 10,000 cells were analyzed in each sample. Each histogram displays the number of cells (ordinate) versus the intensity of fluorescence (abscissa) expressed on a logarithmic scale. Ascites derived from a nonreactive hybridoma was used as a negative control to determine background fluorescence. Monoclonal antibodies were always used at saturating concentrations (1:100-1:500).

Two color fluorescence analysis was accomplished by incubating cells simultaneously with a directly fluorescein-conjugated (FITC) monoclonal antibody (either anti-NKH $1_{A}$, anti-NKH2, or anti-Ia) and a biotin-conjugated monoclonal antibody (either anti-NKH1 $1_{\mathrm{A}}$, antiNKH2, anti-T3, anti-T11, or Leu7). Anti-Ia fluorescence conjugates and anti-T11 biotin conjugates were provided by Coulter Immunology, Hialeah, FL. Leu7 (HNK-1) was obtained from Becton Dickinson \& Co. After incubation at $4^{\circ} \mathrm{C}$ for $30 \mathrm{~min}$, excess antibody was removed by washing two times and cells were then incubated for $30 \mathrm{~min}$ at $4^{\circ} \mathrm{C}$ with avidin-conjugated phycoerythrin (AV-PE). Background fluorescence was determined by incubating cells as above with a nonreactive fluorescein-conjugated antibody and a nonbiotinylated antibody followed by AV-PE. In some experiments, directly fluorescein-conjugated antibodies (anti-NKH1 $1_{A}$ or anti-NKH2) were used simultaneously with directly phycoerythrin-conjugated antibodies B73.1, (Leul1c, Becton Dickinson \& Co.). After two additional washes, cells were fixed in $1 \%$ formaldehyde and analyzed using an Epics V (Coulter Electronics). The simultaneous analysis of green and red immunofluorescence was obtained from a single laser exciting both FITC and PE at $488 \mathrm{~nm}$. Electronic compensation for the small overlaps of fluorescein fluorescence on the PE detector and PE fluorescence on the fluorescein detector yielded signals essentially identical to those with either reagent used alone. 10,000 cells were analyzed in each sample and results displayed as an orthographic projection looking down on an $\mathrm{x}, \mathrm{y}$ axis plotting $\log$ green fluorescence (FITC) versus log red fluorescence (PE).

Complement lysis experiments. Cells were incubated with either anti-NKH1 $1_{A}$ or anti-NKH2 antibodies at a concentration of $25 \times 10^{6}$ cells/ml in RPMI 1640 containing $2.5 \%$ pooled human AB serum for $30 \mathrm{~min}$ at room temperature. Cells were then washed in serum-free medium and rabbit complement was added at 1:10 final dilution in serum-free medium for $45 \mathrm{~min}$ at $37^{\circ} \mathrm{C}$. In all experiments presented here, the entire procedure was repeated two times.

Purification of $\mathrm{NKH} 2+$ cells. For enrichment of $\mathrm{NKH} 2+$ cells by immune rosetting technique, PBMC were incubated at a concentration of $25 \times 10^{6}$ cells $/ \mathrm{ml}$ for $30 \mathrm{~min}$ at $4^{\circ} \mathrm{C}$ with saturating amounts of anti-Ia, anti-Mo2, and anti-T4. Unbound antibody was removed by two wash steps. To form immunorosettes, monoclonal antibodytreated cells were mixed with a $10 \%$ anti-Ig coated erythrocyte suspension at a ratio of $0.75 \mathrm{ml}$ for $10^{8}$ peripheral blood lymphocytes (PBL). The mixture was pelleted $(300 \mathrm{~g}, 10 \mathrm{~min})$ and incubated for $20 \mathrm{~min}$ at $4^{\circ} \mathrm{C}$. Ig-coated erythrocytes were prepared as previously described (18). The red cell leukocyte mixture was resuspended vigorously and rosetted cells were separated from nonrosetting cells by $\mathrm{F} / \mathrm{H}$ density gradient sedimentation. Rosetted (T4, Mo2, Ia)+ cells were recovered from the F/H pellet by hypotonic lysis. Subsequently, cells from both fractions were washed two times and used for additional purification or functional assays. The entire procedure was conducted in RPMI 1640 containing $5 \%$ pooled human AB serum. Viability was consistently $>95 \%$ in all cell fractions.

Nonrosetting lymphocytes (T4, Mo2, Ia)- were subsequently separated into $\mathrm{NKH} 2$ - and $\mathrm{NKH} 2+$ fractions using a cell-sorting procedure. Briefly, rosette negative cells (T4, Mo2, Ia)- were incubated with anti-NKH2 for $30 \mathrm{~min}$ at $4^{\circ} \mathrm{C}$, washed twice, and then incubated with 
GM-FITC for an additional $30 \mathrm{~min}$ at $4^{\circ} \mathrm{C}$. After two additional washes, $\mathrm{NKH} 2$ + fluorescent cells were separated from nonfluorescent cells using an Epics V flow cytometer (Coulter Electronics). Background fluorescence was determined with a nonreactive IgM antibody and positive cells were sorted in $10 \%$ pooled human $\mathrm{AB}$ serum at a rate of 3,000 cells/s. Cells were then washed twice and suspended in RPMI 1640 containing $5 \%$ pooled human $\mathrm{AB}$ serum for functional assays and cytocentrifuge smears.

Generation of human cloned cell lines. Methods for generation of human NK cloned cell lines have been described in detail $(4,5)$. Briefly, clones were obtained using a limiting dilution technique. Either PBMC or LGL were cloned at 1 cell/well on a feeder layer of autologous irradiated (5,000 rad) PBMC plus either PHA $(2 \mu \mathrm{g} / \mathrm{ml})$ or allogeneic or autologous irradiated (5,000 rad) EBV transformed B cells. Selected colonies were expanded by addition of culture medium containing lymphocyte-conditioned medium (LCM) (10-15\% final dilution) every $3 \mathrm{~d}$. Culture medium was RPMI 1640 supplemented with $1 \%$ penicillin-streptomycin, $1 \%$ sodium pyruvate, and $20 \%$ human AB serum. All cell lines used in these studies have been subcloned at least two times at 100 cells/well on a feeder layer of autologous irradiated PBMC plus irradiated EBV transformed B cells.

Preparation of LCM. LCM was produced by stimulating whole PBMC at a concentration of $2.5 \times 10^{6} / \mathrm{ml}$ for $2 \mathrm{~h}$ with $5 \mu \mathrm{g} / \mathrm{ml}$ PHA (Wellcome Research Laboratories, Beckenham, England), $5 \mathrm{ng} / \mathrm{ml}$ phorbol myristate acetate (Sigma Chemical Co., St. Louis, MO), and 5,000 rad irradiated Laz $388\left(0.5 \times 10^{6} / \mathrm{ml}\right)$. The cells were then washed four times to remove the mitogens and resuspended in RPMI 1640 supplemented with $2.5 \%$ human $A B$ serum. After $40 \mathrm{~h}$ of incubation at $37^{\circ} \mathrm{C}$, the supernatants were harvested, passed through $0.45-\mu \mathrm{m}$ filters, and stored at $-70^{\circ} \mathrm{C}$.

Cytotoxicity assays. Cytotoxicity assays were performed according to a standard chromium release method previously described (4). All experiments were done in triplicate using $\mathrm{V}$ bottom microtiter plates. Medium was RPMI 1640 plus 5\% pooled human AB serum and $1 \%$ penicillin streptomycin. Assays were performed at various effector/ target ratios using 5,000 target cells/well. JM and Molt-4 are T cell leukemia cell lines whereas K562 was established from a patient with chronic myelogenous leukemia.

${ }^{125}$ I surface labeling and immunoprecipitation of antigens from JT3 cloned cells. Cells were surface labeled with ${ }^{125}$ I (New England Nuclear, Boston, MA) using a standard lactoperoxidase method previously described (5). $2 \times 10^{7}$ viable, proliferating JT3 cells were washed with RPMI 1640 and resuspended in PBS and labeled with $1 \mu \mathrm{Ci}{ }^{125} \mathrm{I}$ for $15 \mathrm{~min}$ at room temperature followed by addition of $100 \mu \mathrm{l} \mathrm{NaI}(1$ $\mathrm{mol} / \mathrm{liter}$ ). Labeled cells were then harvested and washed three times in cold RPMI 1640. Cell lysate was prepared by resuspending the cell pellet in $300 \mu$ l RIPA buffer, pH 7.5, containing $1 \%$ Triton X-100, $0.15 \mathrm{M} \mathrm{NaCl}, 0.01 \mathrm{M} \mathrm{NaH}_{2} \mathrm{PO}_{4}, 1 \mathrm{mM}$ EDTA, $1 \mathrm{mM}$ EGTA, $1 \mathrm{mM}$ $\mathrm{NaF}, 1 \mathrm{mM}$ phenylmethylsulfonyl fluoride, and Trypsin inhibitor and agitated for $40 \mathrm{~min}$ at $4^{\circ} \mathrm{C}$. Cell lysates were stored at $-70^{\circ} \mathrm{C}$ before use.

Immune precipitation of $\mathrm{N} 901$ and $\mathrm{NKH}_{\mathrm{A}}$ antigens were carried out using preformed complexes of rabbit anti-mouse Ig and specific monoclonal antibody as previously described (19). Precipitation of NKH2 antigen was performed using anti-NKH2 antibody bound to $\mathrm{CnBr}$-activated Sepharose 4B. Before being bound to $\mathrm{CnBr}$-activated Sepharose 4B, anti-NKH2 was purified using a standard ammonium sulfate precipitation procedure. In both cases, macromolecular aggregates were removed from cell lysate by ultracentrifugation for $30 \mathrm{~min}$ at $100,000 \mathrm{~g}$. Cell lysates were then precleared three times by incubation at $4^{\circ} \mathrm{C}$ for $1 \mathrm{~h}$ with either formalin fixed Staph A bacteria and/or preformed complexes of rabbit anti-mouse Ig and nonspecific monoclonal antibody. Aliquots of precleared lysate were then incubated with specific preformed complexes or with antibody-coated Sepharose beads for $2 \mathrm{~h}$ at $4^{\circ} \mathrm{C}$. Immune precipitates were then washed four times with radioimmune precipitation assay buffer as above and dissolved in SDS- polyacrylamide gel electrophoresis (SDS-PAGE) sample buffer and loaded onto separate slots on a $10 \%$ polyacrylamide slab gel. Identical aliquots of immune precipitation were run in nonreduced and reduced conditions after addition of 2-mercaptoethanol to SDS-PAGE sample buffer. Gels were dried and radiolabeled precipitates were visualized using standard methods (20).

\section{Results}

Generation and cellular reactivity of anti-NKH1 $1_{A}$ and antiNKH 2 monoclonal antibodies. Anti-NKH1 $1_{\mathrm{A}}$ and anti-NKH2 hybridoma antibodies were obtained in a series of fusion experiments with mouse spleen cells immunized against cloned JT3 cells. JT3 is a human cloned NK cell line that has been previously described in detail (5). This clone was derived from purified large granular lymphocytes initially stimulated with PHA and medium containing IL-2. For $>18$ mo, JT3 cells have been maintained in culture and have been found to display stable phenotype (T3-T4-T8-T11+N901+) and cytotoxic activity when tested against a large panel of in vitro established cell lines. The initial screening strategy was designed to rapidly identify antibodies with preferential reactivity for NK cells and without reactivity with either mature $T$ cells or $B$ cells.

Anti-NKH $1_{\mathrm{A}}$ and anti-NKH2 hybridoma supernatants were initially selected because of their capacity to kill JT3 cells in the presence of complement, whereas they were not able, under identical conditions, to lyse either an autologous EBV transformed B cell line or an autologous MHC restricted cytotoxic $\mathrm{T}$ cell clone. Antibody-producing hybridomas were subsequently recloned two times by limiting dilution and immune ascites were produced. Anti-NKH1 $1_{A}$ and anti-NKH2 were found to be IgM antibodies by Ouchterlony immunoprecipitations using standard reagents.

Reactivity of both anti-NKH1 $1_{A}$ and anti-NKH2 antibodies was tested on purified populations of lymphoid and nonlymphoid cells by indirect immunofluorescence assays and subsequent analysis using either a FACS I or Epics V flow cytometer. Both antibodies were strongly reactive with JT3 immunizing cells. In addition, they were found to react with a small population of lymphocytes present in peripheral blood (Table I A). Monocytes, granulocytes, platelets, red cells, thymocytes, and PHA-activated E+ cells were negative. The immunofluorescence reactivity of anti-NKH2 with JT3 cells, PBL, monocytes, and granulocytes is demonstrated in Fig. 1. Immunofluorescence histograms obtained on the same cell fractions with anti-NKH1 $1_{A}$ were almost identical (data not shown). The selective expression of $\mathrm{NKH}_{\mathrm{A}}$ and $\mathrm{NKH} 2$ was also demonstrated by further analysis of a series of 14 lymphohematopoietic cell lines derived from either virally transformed cells or tumor cells which were all found to be negative (Table I).

The morphology of $\mathrm{NKH1}_{\mathrm{A}^{+}}$and $\mathrm{NKH} 2+$ cells in unstimulated peripheral blood was determined following purification of these cells by immunofluorescence cell sorting. For this purpose, peripheral blood lymphocytes from two individual donors were incubated with either anti-NKH1 $1_{\mathrm{A}}$ or anti-NKH2 plus GM-FITC. Small numbers $(\sim 50,000$ cells) of either $\mathrm{NKH}_{\mathrm{A}^{+}}$or $\mathrm{NKH} 2+$ cells were then purified using an Epics $\mathrm{V}$ and cytocentrifuge smears were prepared and analyzed. It was found that both $\mathrm{NKHl}_{\mathrm{A}^{+}}$and $\mathrm{NKH} 2+$ purified fractions consisted almost entirely $(>90 \%)$ of large granular lymphocytes and it was not possible to distinguish morphologically between 


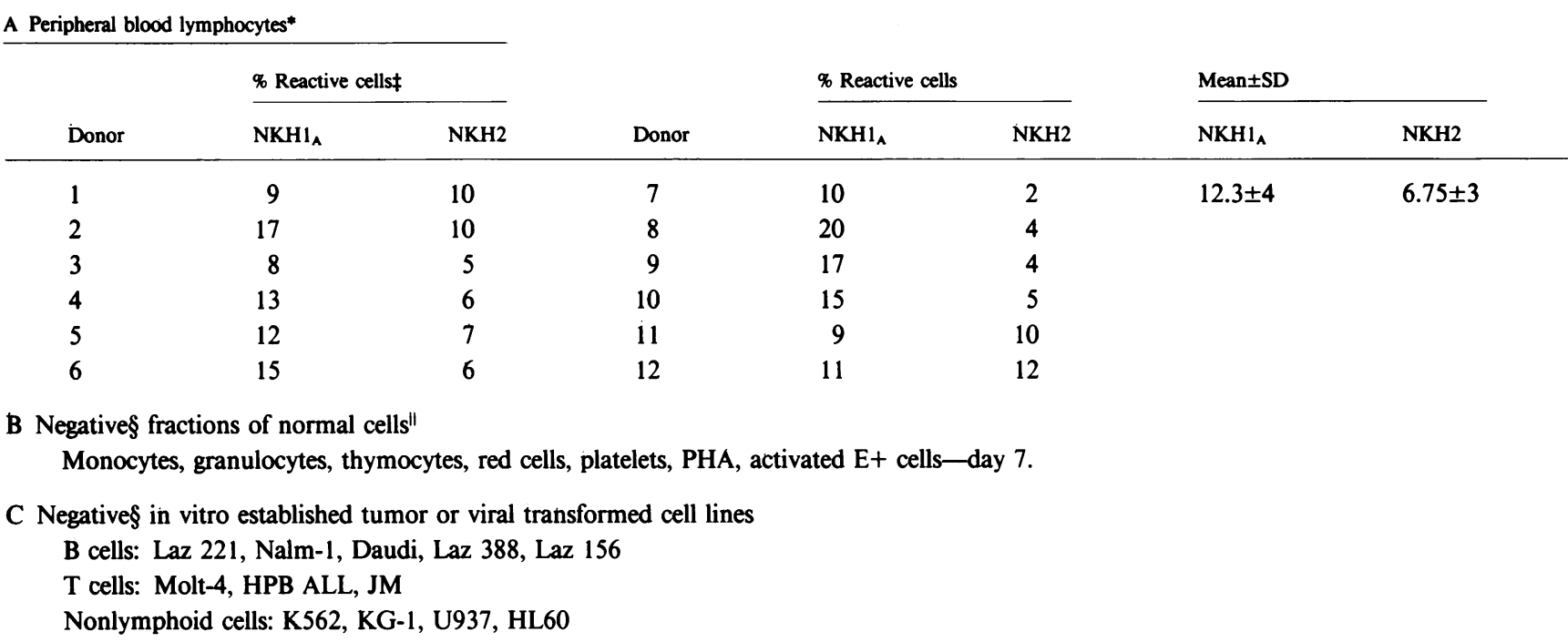

* Nonadherent PBMC. ¥ Percentage of reactive cells was calculated by substrating background fluorescence obtained with an ascites derived from a nonproductive hybridoma. $\S$ Less than $3 \%$ reactive cells per cell fraction. "At least three individual experiments per fraction.

\section{NKH2 ANTIGEN EXPRESSION}

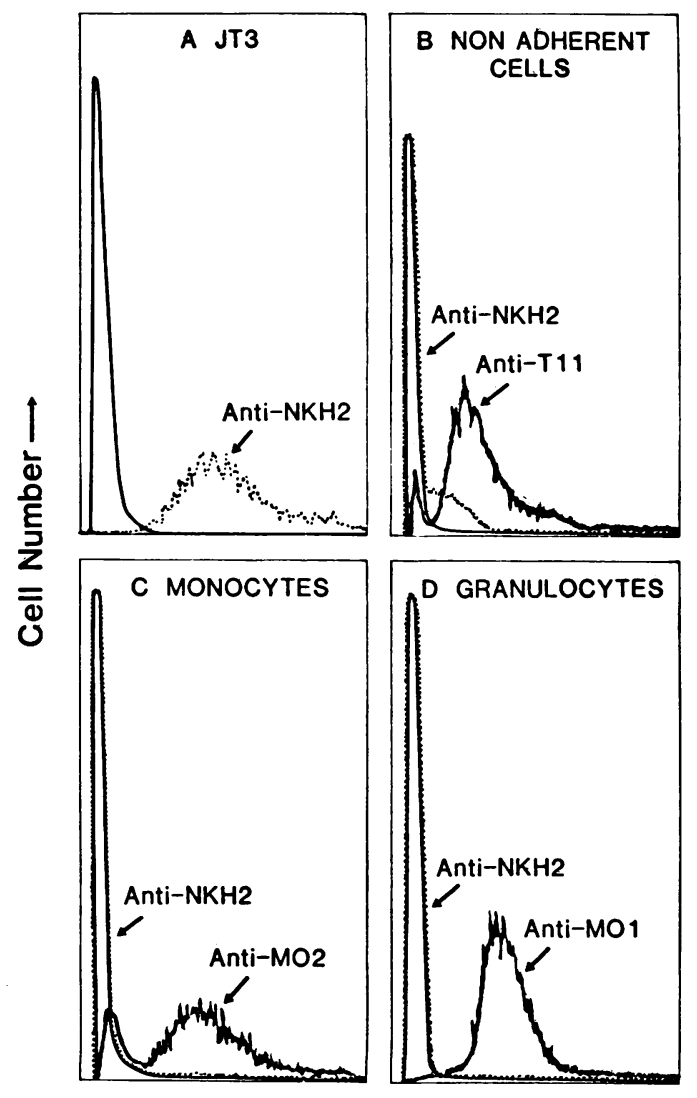

Fluorescence Intensity $\longrightarrow$

Figure 1. NKH2 antigen expression. Nonadherent cells, monocytes, and granulocytes were purified as described in Methods and tested for NKH2 expression by an indirect immunofluorescence assay. Anti-T11, anti-Mo2, and anti-Mol were used to assess the quality of the purification.
$\mathrm{NKH}_{\mathrm{A}^{+}}$and $\mathrm{NKH} 2+$ cells. A Wright Giemsa stained cytocentrifuge smear of $\mathrm{NKH} 2+$ circulating cells is shown in Fig. 2. The finding that both antibodies selected for their reactivity with NK active clones were also both reactive with LGL was consistent with previous studies that have demonstrated that virtually the entire NK activity present in peripheral blood was mediated by a small fraction of lymphocytes which can be identified morphologically because of their larger size and the presence of azurophilic granules in the cytoplasm (21).

As presented in Table I A, anti-NKH $1_{\mathrm{A}}$ reacted with $\sim 12 \%$ of unseparated PBMC and anti-NKH2 reacted with a smaller number of cells, $\sim 7 \%$. However, considerable variability was found from one donor to another when one compared the respective percentages of $\mathrm{NKH}_{A}$ and $\mathrm{NKH} 2+$ cells. For example, donors 1,11 , and 13 had similar percentages of $\mathrm{NKH}_{\mathrm{A}^{+}}$and $\mathrm{NKH} 2+$ cells, whereas in donors $7,8,9$, and 10 , anti- $\mathrm{NKH}_{\mathrm{A}}$ reacted with at least three times more cells than anti-NKH2. Since it was established that $\mathrm{NKH}_{\mathrm{A}}$ and NKH2 were both present on minor populations of circulating lymphocytes with LGL morphology, we subsequently tried to determine whether LGL coexpressed both antigens or whether some LGL could exclusively express one or the other antigen. To address this question, LGL-enriched fractions were obtained using an immunorosette depletion technique described in Methods. Using this method, PBMC were separated in two fractions (T4, Mo2, Ia)+ (LGL depleted) and (T4, Mo2, Ia)(LGL enriched). Anti-T4, anti-Ia and anti-Mo2 antibodies were utilized in these experiments because it had been previously been shown that $\mathrm{T} 4$, Ia, and Mo2 antigens were not expressed on LGL to any significant degree $(8,14,22)$. This procedure resulted in the specific depletion of the majority of T lymphocytes (T4+), B lymphocytes (Ia+), and monocytes $(\mathrm{Ia}+, \mathrm{Mo2}+)$ from circulating PBMC. Over a series of 10 experiments, $\sim 10-20 \%$ of the starting population of PBMC was recovered in the (T4, Mo2, Ia) - fraction and a 4-5-fold enrichment in both $\mathrm{NKH}_{\mathrm{A}^{+}}$and $\mathrm{NKH} 2+$ cells was obtained in this immunorosette depleted population. 


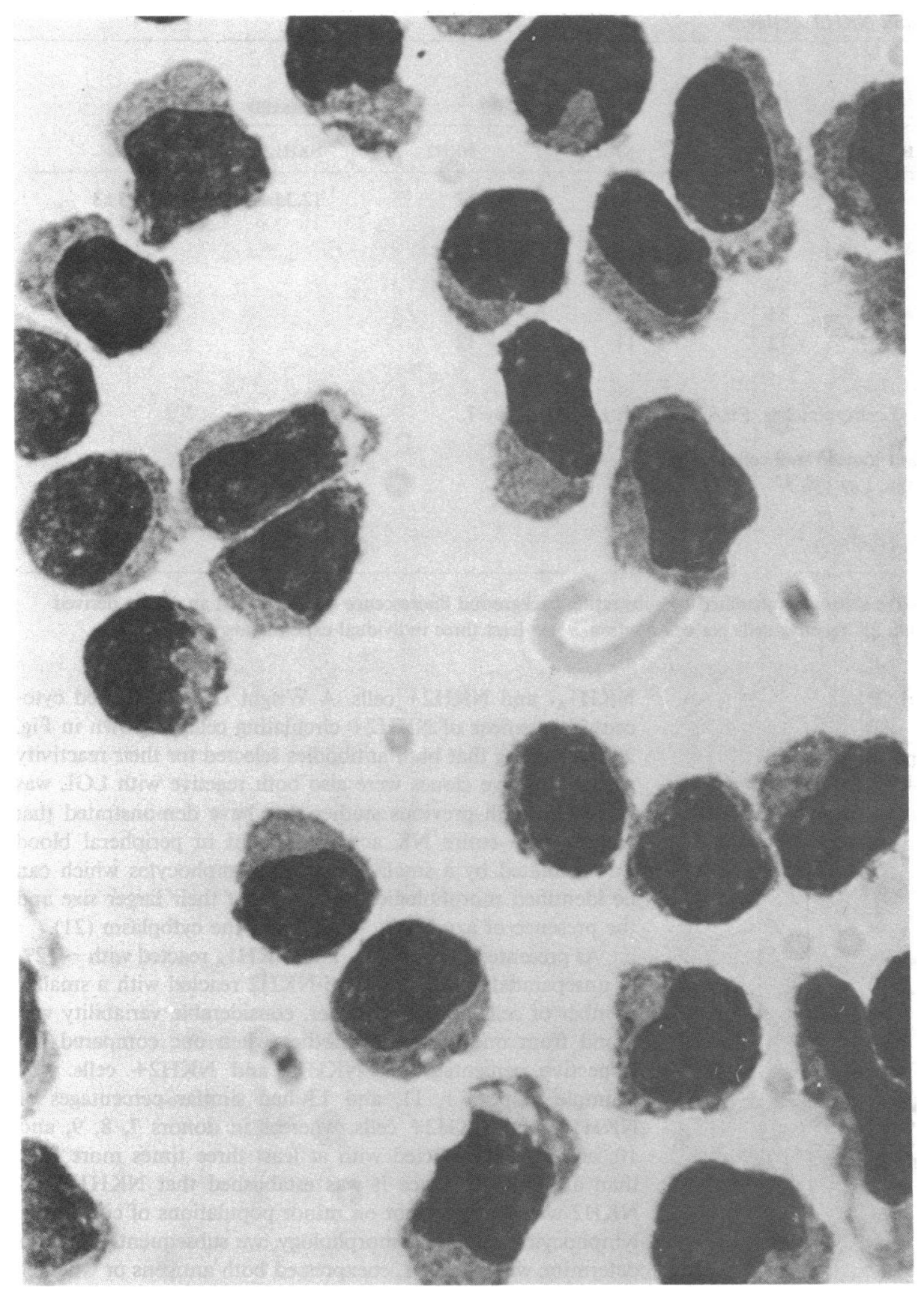

Figure 2. Morphology of $\mathrm{NKH} 2+$ cells in fresh uncultured human peripheral blood. Approximately 50,000 cells were sorted following indirect immunofluorescence assay with anti-NKH2 plug GM-FITC using an Epics V. Cytocentrifuge smears were prepared and stained with Wright-Giemsa stain.
To investigate the possible presence of both $\mathrm{NKH}_{\mathbf{A}}+$ NKH2 - and $\mathrm{NKH}_{1}-\mathrm{NKH} 2+$ LGL subsets in peripheral blood, LGL-enriched fractions obtained by immunorosette depletion were treated with either anti-NKH1 ${ }_{A}$ or anti-NKH2 plus complement. After lysis, remaining viable cells were tested using indirect immunofluorescence assays and cell sorter analysis for expression of $\mathrm{NKH}_{\mathrm{A}}$ and $\mathrm{NKH} 2$. In these experiments, it was found that treatment with one or the other antibody did not totally eliminate cells expressing the reciprocal antigen. A representative experiment illustrating these results is presented in Fig. 3. Unseparated PBMC from this donor contained $14 \%$ $\mathrm{NKH}_{\mathrm{A}}+$ cells and $9 \% \mathrm{NKH} 2+$ cells (Fig. $3 A$ ). After immunorosette depletion, $69 \% \mathrm{NKH}_{\mathrm{A}}+$ cells and $30 \% \mathrm{NKH} 2+$ cells were present in the LGL enriched (T4, Mo2, Ia)- fraction
(Fig. 3 B). When cells from this latter fraction were reanalyzed following treatment with anti-NKH2 plus complement, the reactivity of anti-NKH2 was reduced to $3 \%$, whereas the reactivity of anti-NKH1 $1_{A}$ was $68 \%$ (Fig. $3 C$ ). Reciprocally, following lysis with anti-NKH1 $1_{A}$, the percent cells reactive with $\mathrm{NKHI}_{A}$ was reduced to $15 \%$, but $35 \%$ of $\mathrm{NKH} 2+$ cells were still present (Fig. $3 \mathrm{D}$ ). As shown in Fig. 3, complement lysis with anti-NKH2 was generally more efficient than with anti-NKH1 $1_{A}$. Using the latter antibody, it was very difficult to eliminate cells displaying very low antigen density. This series of experiments strongly suggested that even though both antigens were exclusively expressed on LGL populations, both

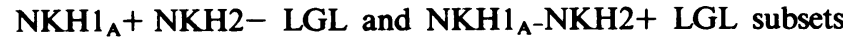
were also present in peripheral blood. 


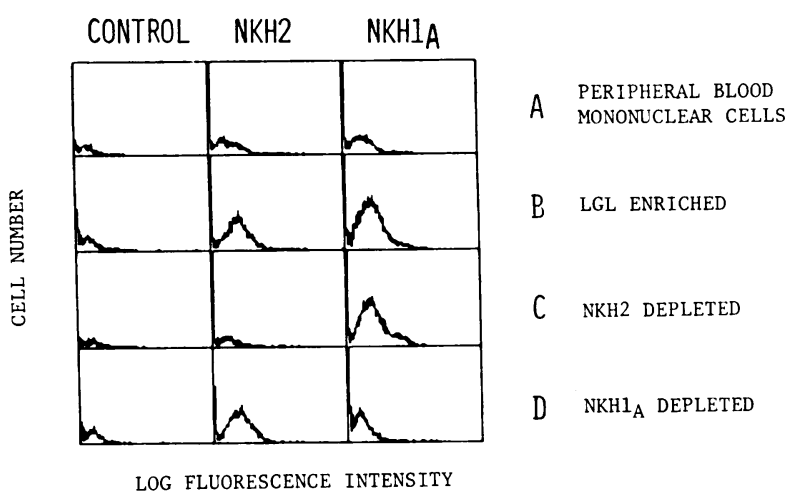

Figure 3. Reactivity of anti-NKH1 $1_{A}$ and anti-NKH2 with $\mathrm{PBL}$ and purified fractions of LGL. PBMC, LGL enriched, NKH2 depleted, and $\mathrm{NKH}_{\mathrm{A}}$ depleted fractions were obtained as described in Methods. Aliquots of each fraction were tested simultaneously by indirect immunofluorescence for reactivity with either anti-NKH2 or anti$\mathrm{NKH}_{\mathrm{A}} \cdot 10,000$ cells were analyzed in each sample using the Epics V. Anti-T6 was used as control antibody. Percent-positive cells was calculated by subtracting background fluorescence obtained with antiT6, which was $<5 \%$ in each instance. $(A)$ Reactivity of anti-NKH $1_{\mathrm{A}}$ $(14 \%)$ and anti-NKH2 $(9 \%)$ with PBL. (B) LGL-enriched (T4, Mo2, la negative) fraction obtained as described in Results. Anti- $\mathrm{NKHI}_{\mathrm{A}}$ : 69\%; anti-NKH2: $30 \%$. $(C)$ Reanalysis of fraction B after treatment with anti-NKH2 plus complement. Anti-NKH1 $1_{\mathrm{A}}: 68 \%$; anti-NKH2: 3\%. (D) Reanalysis of fraction B after treatment with anti-NKH $\mathrm{I}_{\mathrm{A}}$ plus complement. Anti-NKH1 ${ }_{\mathrm{A}}$ : $15 \%$; anti-NKH2: $35 \%$.

Two color immunofluorescence analysis of nonadherent $P B M C$. Both anti-NKH1 $1_{\mathrm{A}}$ and anti-NKH2 were obtained after immunization of mice with a single population of cloned cells, and both antibodies reacted specifically with LGL, which represent only a minor fraction of circulating lymphocytes. It was therefore likely that in addition to LGL expressing either $\mathrm{NKH}_{\mathrm{A}}$ or $\mathrm{NKH} 2$, a third population of cells could coexpress both antigens. To demonstrate this point, PBMC were analyzed using two color immunofluorescence with both anti-NKH $1_{A}$-FITC and anti-NKH2-biotin/AV-PE. In a similar fashion, $\mathrm{NKH}_{\mathrm{A}}$-positive cells and $\mathrm{NKH} 2$-positive cells were also tested for coexpression of T3, T11, and Ia antigens. Before dual color analysis, freshly isolated mononuclear cells were depleted of monocytes by a 1-h adherence in large plastic dishes at $37^{\circ} \mathrm{C}$, but no other enrichment procedures were used in order to avoid potential artifacts that could result from further immunologic manipulation. As shown in Fig. 4, a distinct subset of $\mathrm{NKH}_{\mathrm{A}}$ positive cells coexpresses $\mathrm{NKH} 2$ antigen. In addition, the large majority of both $\mathrm{NKH}_{\mathrm{A}}$ or NKH2-positive cells coexpressed T11 antigen, a smaller subset coexpressed $\mathrm{T} 3$ antigen, but very few cells also coexpressed Ia antigens. Specifically, of the $\mathrm{NKHl}_{\mathrm{A}}$ positive cells in this individual, $29 \%$ were $\mathrm{NKH} 2+, 39 \%$ were $\mathrm{T} 3+, 83 \%$ were $\mathrm{T} 11+$ and $1 \%$ were Ia + . Within the NKH2-positive population, similar percentages of cells coexpressed these same antigens: $38 \%$ were $\mathrm{T} 3+, 79 \%$ were $\mathrm{T} 11+$, and $3 \%$ were $\mathrm{Ia}+$.

Expression of $\mathrm{NKHI}_{A}$ and $\mathrm{NKH} 2$ antigens on human cloned NK cell lines. In addition to studying unstimulated peripheral blood cells, a large panel of cloned NK cell lines was also used in order to evaluate the expression of $\mathrm{NKH}_{\mathrm{A}}$ and $\mathrm{NKH} 2$ at the single cell level. As with the two color immunofluorescence studies, characterization of these NK clones also allowed an analysis of the coexpression of $\mathrm{NKH}_{\mathrm{A}}$ and NKH2 with additional antigens such as T3, T11, and N901. The reactivity of anti-NKH1 $1_{A}$ and anti-NKH2 was tested using a series of nine cloned NK cell lines (Table II). JT1, JT3, JT9, and JT10 have been previously described in detail $(5,6)$. JT11 was a clone derived from the same donor. It was found to express the NKTa clonotypic determinant as well as JT9 and JT10 (6). The lytic specificity of JT11 was superimposable to that of JT9 and JT10 when tested against a panel of 15 in vitro established cell lines (unpublished data). Like JT11, JT15 and JT16 were derived from peripheral blood lymphocytes stimulated by an autologous EBV transformed B cell line plus conditioned medium containing IL-2, and were initially selected for their capacity to kill K562 cells. JT15 cells had a mature $\mathrm{T}$ cell phenotype coexpressing $\mathrm{T} 3, \mathrm{~T} 8$, and T11, but did not react with the anti-NKTa anti-clonotypic antibody. JT16 has a phenotype similar to that of JT3 using the presently available monoclonal antibodies. $\mathrm{JT}_{\mathrm{A}} 17$ was derived from a separate donor and obtained from PBL stimulated by allogeneic cells. Its phenotype was unique, since $\mathrm{JT}_{\mathrm{A}} 17$ cells express the maturation antigen $\mathrm{T} 3$, but not $\mathrm{T} 4$ and T8. Finally, $\mathrm{JT}_{\mathrm{B}} 18$ was derived from $\mathrm{PBL}$ of a third donor, initially stimulated by PHA and medium containing IL-2. Each JT clone has been expanded in conditioned medium containing IL-2 and has maintained a stable phenotype in culture for $>3 \mathrm{mo}$.

As shown in Table II, $\mathrm{NKH}_{\mathrm{A}}$ was present on all clones that had been selected on the basis of one unique criteria, e.g., the capacity of killing K562 cells without apparent preimmunization. In addition, it was found that the reactivity of anti$\mathrm{NKH}_{\mathrm{A}}$ on these cloned NK cell lines was virtually superimposable to that of the previously described anti-N901 antibody.

The expression of $\mathrm{NKH} 2$ was distinct from that of $\mathrm{NKH}_{\mathrm{A}}$ since only four of the nine $\mathrm{NK}$ clones were $\mathrm{NKH} 2+. \mathrm{NKH}_{\mathrm{A}}$ and NKH2 were coexpressed on JT1, JT3, and JT16 and $\mathrm{JT}_{\mathrm{A}} 17$ cells. JT1 has a very unique phenotype, since it does not express any $\mathrm{T}$ cell associated antigens. JT3 and JT16 are phenotypically identical when tested with the presently available antibodies. Both clones are T3-,T4-,T8-,T11+,N901+, and this appears to represent one very common phenotype of fresh peripheral blood NK cells (8). NKH2 was not present on JT9, JT10, and JT11, which all express the NKTa clonotypic determinant, and was also not found on JT15, which is an additional clone with mature $\mathrm{T}$ cell $(\mathrm{T} 3+)$ phenotype. Nevertheless, $\mathrm{JT}_{\mathrm{A}} 17$ cells, which also express $\mathrm{T} 3$ antigen, were very strongly NKH2+, which indicated that at least some NK cells with mature $\mathrm{T}$ cell phenotype can express this antigen as well as other $\mathrm{NK}$ active cells. Interestingly, $\mathrm{JT}_{\mathrm{B}} 18$, previously considered to share identical surface markers with JT3 and JT16, was found to be NKH2-. It was also noted that for each clone the reactivity of anti-NKH 2 was either $<1 \%$ of the cells or $>95 \%$. In addition, each $\mathrm{NKH} 2+$ clone was found to express relatively large amounts of antigen, and the reactivity with anti-NKH2 antibody was stable from one determination to another. The expression of $\mathrm{NKH} 2$ was also tested using nine additional, well characterized MHC restricted human T cell clones without NK activity (kindly provided by Dr. Stefan Meuer, Johannes-Gutenberg-Universität, Mainz, Federal Republic of Germany), and all were found to be negative (data not shown). 

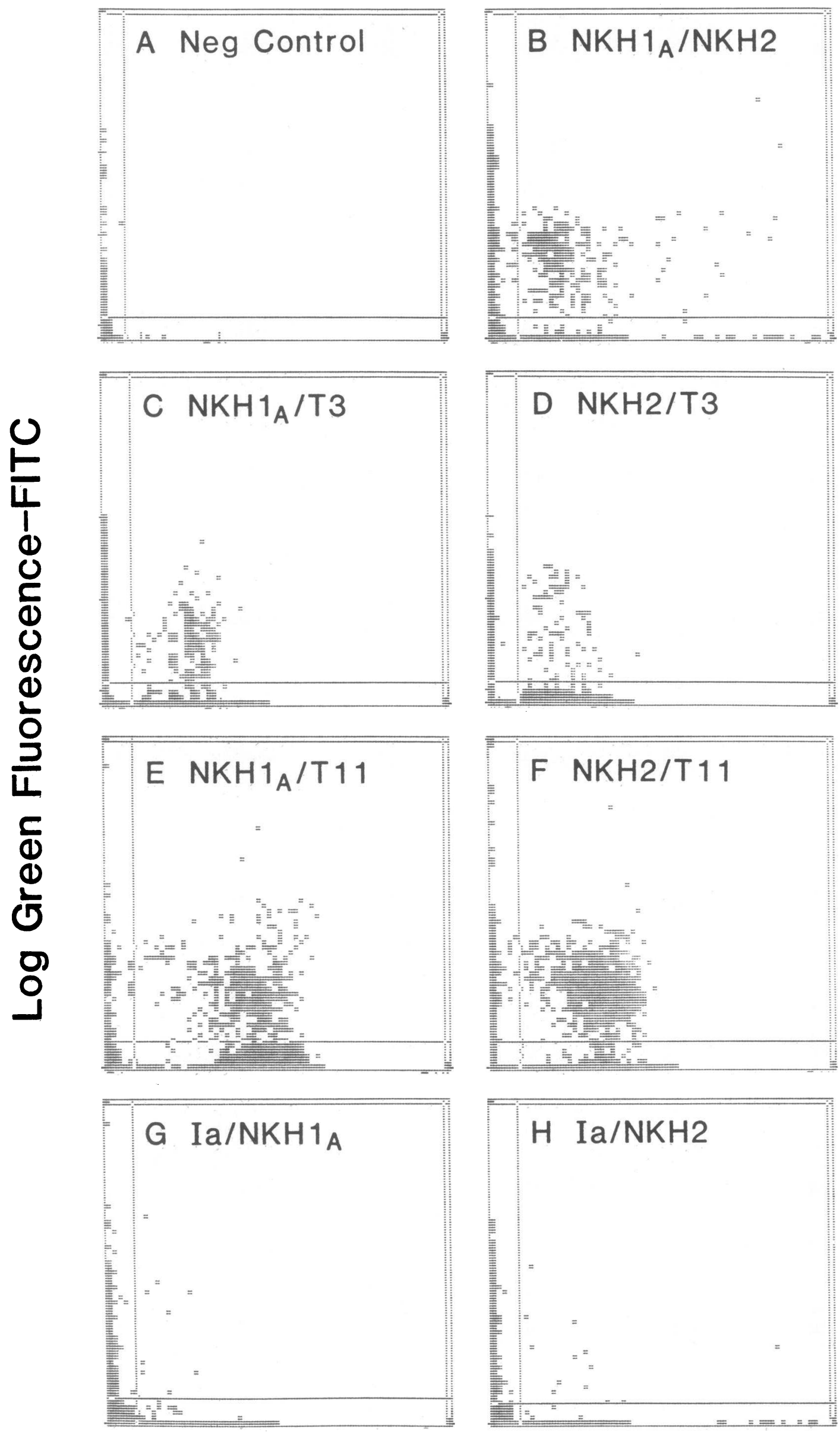

Figure 4. Two color immunofluorescence analysis of nonadherent PBMC. Cells were analyzed for simultaneous expression of two antigens using a combination of a directly fluoresceinconjugated monoclonal antibody (either anti$\mathrm{NKH}_{\mathrm{A}}$, anti-NKH2, or anti-Ia) and a biotin-conjugated monoclonal antibody (either anti-NKH1 ${ }_{A}$, anti-NKH2, anti-T3, or anti-T11) followed by incubation with A.V-PE. 10,000 cells in each sample were analyzed using the Epics V, which presented the data as an orthographic projection plotting log green fluorescence (FITC) vs. log red fluorescence (AV-PE) for each combination. Lines within the matrix were used to define four quadrants: GR, positive for both green and red fluorescence; $G$, positive for green fluorescence only; $R$, positive for red fluorescence only; and NN, negative for both green and red fluorescence. For example, results for samples $A$ and $B$ were as follows: sample A: GR 0\%, $\mathrm{G}<1 \%, \mathrm{R}<1 \%$, NN $>99 \%$; sample B: GR $2.5 \%, \mathrm{G} 6 \%$, R $2.5 \%$, NN $89 \%$. 
Table II. Expression of $\mathrm{NKHI}_{A}$ and $\mathrm{NKH} 2$ on Cloned Human $\mathrm{NK}$ Cell Lines

\begin{tabular}{|c|c|c|c|c|c|c|c|c|c|c|}
\hline \multirow[b]{2}{*}{ Clone } & \multirow[b]{2}{*}{ Origin } & \multirow[b]{2}{*}{ Initial stimulation } & \multicolumn{6}{|c|}{ Phenotype } & \multicolumn{2}{|c|}{ Reactivity } \\
\hline & & & T3 & $\mathrm{T} 4$ & T8 & T11 & NKTa & 901 & $\mathrm{NKHI}_{\mathrm{A}}$ & NKH2 \\
\hline JT1 & LGL & PHA & - & - & - & - & - & + & + & + \\
\hline JT3 & LGL & $\operatorname{Laz} 461^{*}$ & - & - & - & + & - & + & + & + \\
\hline JT9 & PBL & PHA & + & - & + & + & + & + & + & - \\
\hline JT10 & PBL & PHA & + & - & + & + & + & + & + & - \\
\hline JT11 & PBL & Laz 461 & + & - & + & + & + & + & + & - \\
\hline JT15 & PBL & Laz 461 & + & - & + & + & - & + & + & - \\
\hline JT16 & PBL & Laz 461 & - & - & - & + & - & + & + & + \\
\hline $\mathrm{JT}_{\mathrm{A}} 17$ & PBL & Allogeneic PBL & + & - & - & + & - & + & + & + \\
\hline $\mathrm{JT}_{\mathrm{B}} 18$ & PBL & PHA & - & - & - & + & - & + & + & - \\
\hline
\end{tabular}

* Laz 461: autologous EBV transformed B cell line.

Functional characterization of $N K H 1_{A}$ and $N K H 2$ subsets in resting peripheral blood. Since both anti- $\mathrm{NKH}_{\mathrm{A}}$ and antiNKH2 are IgM antibodies, it was possible to investigate the potential capacity of each reagent for lysing NK effector cells in human peripheral blood in the presence of complement. For this purpose, peripheral blood mononuclear cells were incubated with either medium, anti-NKH1 $1_{A}$, or anti-NKH2 for $30 \mathrm{~min}$ at room temperature. Anti-N901, which is a nonlytic IgGI antibody directed at NK cells, was used as a control in these experiments. Antibody excess was washed out and complement was then added for $45 \mathrm{~min}$ at $37^{\circ} \mathrm{C}$. This procedure was repeated two times. Subsequently, remaining viable cells were counted, and ${ }^{51} \mathrm{Cr}$-labeled target cells were added. Fig. 5 shows the representative results obtained with PBL from a donor displaying a very high level of spontaneous cytotoxicity against the JM, T cell leukemia line. Treatment of PBL with anti-NKH1 $1_{A}$ plus $\mathrm{C}$ was followed by a virtually complete loss of NK activity, whereas anti-NKH2 treated PBL displayed a level of cytotoxicity similar to that of the control. Similar experiments were done where two additional cell lines, K562 and Molt 4, were used as targets in NK assays following complement lysis, and identical results were found.

These complement lysis experiments suggested that $\mathrm{NKH} 2+$ LGL were functionally distinct from $\mathrm{NKH} 1_{\mathrm{A}}$ LGL and were not displaying strong NK activity. To confirm this point, $\mathrm{NKH} 2+$ cells were purified using cell sorter procedures. In initial experiments, $\mathrm{NKH} 2+$ cells were directly sorted from unseparated PBMC and, as expected from lysis depletion studies, appeared to have very weak cytotoxic activity. However, given the very low percentage of $\mathrm{NKH} 2+$ lymphocytes in unseparated PBMC, interpretation of this data was difficult for several reasons. Firstly, cell sorting procedures were very long, and this may have resulted in cell damage; secondly, sufficient

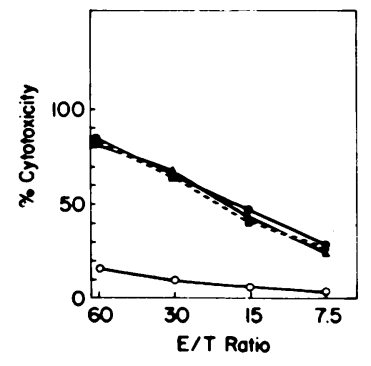

Figure 5. NK activity of fresh uncultured PBM after treatment with either anti-NKH $1_{A}$ or anti-NKH2 antibodies. ๑, PBMC treated with medium plus complement; $\triangle$, PBMC treated with anti-N901; - - , PBMC treated with anti-NKH2; O, PBMC treated with anti-NKH $1_{\mathrm{A}}$. Target cells were ${ }^{51} \mathrm{Cr}$-labeled JM cells (5,000 cells/ well). numbers of purified NKH2+ cells could not be obtained for testing at high effector/target ratios in cytotoxicity assays. Therefore, in subsequent experiments, NKH2 cells were enriched before being sorted using the immunorosette technique described above. PBMC were separated into (T4, Mo2, Ia)+ and (T4, Mo2, Ia) - fractions. Subsequently, the (T4, Mo2, Ia)- LGL enriched subset was sorted into $\mathrm{NKH} 2+$ and NKH2 - cells. Ultimately, cytotoxic activity of five distinct fractions was compared in standard 4-h NK assays: starting population of PBMC, (T4, Mo2, Ia)+ cells, (T4, Mo2, Ia)cells, (T4, Mo2, Ia)- NKH2+ cells, and (T4, Mo2, Ia)NKH2- cells.

Two representative experiments are shown in Fig. 6. As expected, most, if not all, spontaneous cytotoxicity present in human peripheral blood was found in the (T4, Mo2, Ia)fraction, whereas little if any NK activity was displayed by cells of the reciprocal (T4, Mo2, Ia)+ subset. More importantly, in five of six experiments, it was found that NKH2+ LGL had low NK activity, whereas (T4, Mo2, Ia)- NKH2- cells displayed a level of cytotoxicity that was the same or slightly higher than that of the unsorted (T4, Mo2, Ia)- lymphocytes. Only in one of six experiments was the NK activity displayed by $\mathrm{NKH} 2+$ cells almost as strong as that present in the (T4, Mo2, Ia) - fraction. To ensure that the low NK activity displayed by $\mathrm{NKH} 2+$ sorted cells was not due to a blocking effect of anti-NKH2 antibody, we again took advantage of the
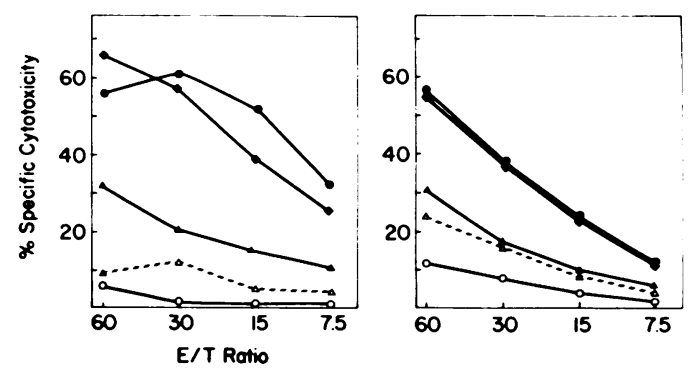

Figure 6. Spontaneous cytotoxicity of various fractions purified from PBL. Purification of various fractions was performed as described in Methods and Results. Target cells were ${ }^{51} \mathrm{Cr}$-labeled JM cells. Left and right panels show two individual experiments, $\Delta$, Unseparated PBMC; O, (T4, Mo2, Ia)+ fraction; $\bullet$, (T4, Mo2, Ia)- fraction; •, (T4, Mo2, Ia)- NKH2- fraction; $\Delta,(\mathrm{T} 4, \mathrm{Mo} 2$, Ia) - NKH2 + fraction. 
cloned cell lines. JT3 cells were separately preincubated with saturating concentrations of anti-NKH2 for either 2 or $16 \mathrm{~h}$ and subsequently assayed for cytotoxicity against ${ }^{51} \mathrm{Cr}$-labeled $\mathrm{K} 562$ and $\mathrm{JM}$ cells. Anti- $\mathrm{NKH1}_{\mathrm{A}}$ was tested in parallel in these experiments. It was found that anti- $\mathrm{NKH} 1_{\mathrm{A}}$ and antiNKH2 did not alter the cytotoxicity of JT3 cells toward these two representative target cells (data not shown).

Characterization of $\mathrm{NKH}_{A}, \mathrm{~N} 901$, and NKH2 antigens. Immunoprecipitation experiments were conducted to identify the molecular weight of the antigens defined by anti-NKH1 and anti-NKH2. An additional antibody, anti-N901, which has been previously shown to react with NK cells, was studied in parallel because the present results suggested that $\mathrm{NKH}_{\mathrm{A}}$ and N901 may represent the same antigens. In addition, the molecular weight of N901 had not been previously described (8).

Immunoprecipitations of the NKH2 antigen from ${ }^{125} \mathrm{I}$ labeled JT3 cells were performed using purified anti-NKH2 antibody bound to $\mathrm{CnBr}$ activated Sepharose $4 \mathrm{~B}$ as described in Methods. Under reducing conditions, anti-NKH2 precipitated a single band of $60,000 \mathrm{~mol} w \mathrm{w}$ in SDS-PAGE. Under nonreducing conditions, two bands, one at $\sim 120,000$ and one at $60,000 \mathrm{~mol} \mathrm{wt}$, were seen in three out of four experiments. In one of four experiments, only a single band at $60,000 \mathrm{~mol}$ wt was obtained in both reducing and nonreducing conditions. It is therefore possible that the 120,000 -mol wt band corresponded to aggregates of the monomeric $60,000-\mathrm{mol}$ wt structure (Fig. 7).

To characterize $\mathrm{NKH}_{\mathrm{A}}$ and $\mathrm{N} 901$ antigens, immunoprecipitations were done using preformed complexes of rabbit anti-mouse Ig with either anti-N901 or anti-NKH1 ${ }_{\mathrm{A}}$ antibodies. These preformed complexes were reacted with ${ }^{125} \mathrm{I}$ surface labeled JT3 cell lysates as described in Methods. As shown in Fig. 8, both anti-N901 and anti-NKH1 $1_{A}$ precipitated a broad band at $\sim 200,000-220,000 \mathrm{~mol} w \mathrm{w}$. Additional experiments were performed in which the precipitates were analyzed using $5-15 \%$ polyacrylamide gradient, and no additional specific bands were identified (data not shown). However, when gradient gels were used, the specific band was seen at a slightly lower molecular weight (180,000-200,000 mol wt) as compared with the $10 \%$ polyacrylamide gels.

To confirm that anti-NKH1 $1_{A}$ and anti-N901 were directed at the same molecule, a series of competitive binding experiments was performed. Advantage was taken of the difference

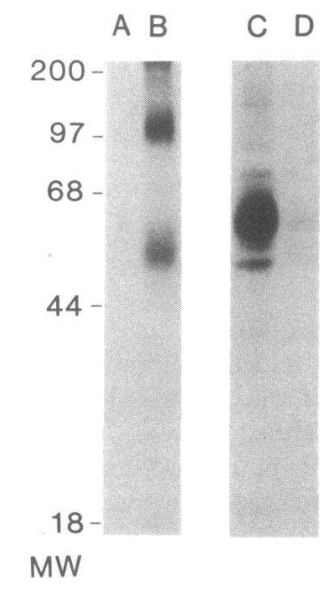

Figure 7. Immunoprecipitation of $\mathrm{NKH} 2$ antigen. Immunoprecipitations of specific antigens from ${ }^{125}$ I-labeled JT3 cells were resolved by SDS-PAGE using 10\% polyacrylamide gels as described in Methods. Controls were overexposed to identify nonspecific bands. Radiolabeled standards were run in parallel with immunoprecipitates. $A$, negative control beads (MY4), nonreduced; $B$, anti-NKH2 coated beads, nonreduced; $C$, negative control beads, reduced; $D$, anti-NKH2 coated beads, reduced.

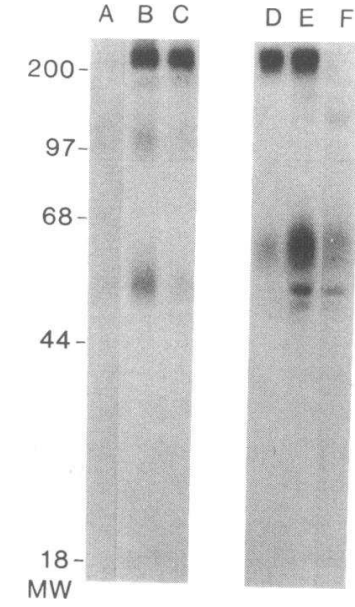

Figure 8. Immunoprecipitation of $\mathrm{NKH}_{\mathrm{A}}$ and $\mathrm{N} 901$ antigens. Immunoprecipitations of $\mathrm{NKH}_{\mathrm{A}}$ and $\mathrm{N} 901$ antigens were performed using preformed complexes and otherwise resolved as described in the legend to Fig. 6. $A$, negative control complex (MY4), nonreduced; $B$, anti-NKH $1_{A}$, nonreduced; $C$, anti-N901, nonreduced; $D$, anti-N901, reduced; $E$, anti-NKH $1_{A}$, reduced; $F$, negative control complex (MY4), reduced.

of isotype between the two antibodies (anti-NKH1 $1_{A}$ being an IgM and anti-N901 being an IgG1). Using isotype specific FITC in indirect immunofluorescence assays, it was found that anti-N901 effectively blocked binding of anti-NKH1 $1_{A}$, whereas anti- $\mathrm{NKHl}_{\mathrm{A}}$ did not significantly affect binding of anti-N901 (data not shown). These results confirmed that both antibodies were specific for the same cell surface antigen and also suggested that the IgG1 antibody (anti-N901) had a higher affinity than the IgM (anti-NKH1 $\left.1_{\mathrm{A}}\right)$.

Coexpression of $\mathrm{NKHI}_{A}$ and $\mathrm{NKH} 2$ with other NK-associated antigens. In order to determine whether the LGL subsets identified by anti- $\mathrm{NKH}_{\mathrm{A}}$ and anti-NKH2 corresponded to those previously identified by other NK-associated antigens, simultaneous two color immunofluorescence studies were undertaken as described previously (Fig. 4) with $\mathrm{T}$ cell antibodies anti-T3 and anti-T11, and with Ia antigen. The other antibodies used in these experiments were HNK-1 (Leu7) and B73.1 (Leu11c). Leu7 is reported to be reactive with the majority of NK active cells in peripheral blood and is also reactive with some $\mathrm{T}$ cells that do not have NK activity $(15,23) . \mathrm{B} 73.1$ is specific for the IgG Fc receptor that is expressed on cells mediating NK and antibody-dependent cellular cytotoxicity (ADCC) as well as mature granulocytes $(16,17)$. The reactivity of B73.1 is similar to that described for NKP-15 $(24,25)$ and VEP 13 (26).

In the two color immunofluorescence analysis shown in Fig. 9, 10,000 cells were analyzed: $21 \%$ of cells were $\mathrm{NKH}_{\mathrm{A}^{+}}, 12 \%$ were $\mathrm{NKH} 2+, 25 \%$ were Leu $7+$, and $9 \%$ were B73.1+. Within the $\mathrm{NKH}_{\mathrm{A}^{+}}$population, $68 \%$ of the cells expressed Leu7 antigen (A) but only $31 \%$ coexpressed B73.1 (C). Within the NKH2+ population, 79\% coexpressed Leu7 antigen (B) but only $20 \%$ also expressed B73.1 (D). Within the Leu7+ population, $50 \%$ of cells coexpressed $\mathrm{NKH}_{\mathrm{A}}$ antigen (A) but only $36 \%$ also expressed NKH2 (B). Within the B73.1+ population, $71 \%$ of cells coexpressed $\mathrm{NKH}_{\mathrm{A}}$ (C) but only $20 \%$ of cells also expressed NKH2 (D). These results demonstrate that normal peripheral blood contains populations of cells that coexpress $\mathrm{NKH}_{\mathrm{A}}$ and Leu7 (A), NKH2 and Leu7 (B), $\mathrm{NKH}_{\mathrm{A}}$ and B73.1 (C), and $\mathrm{NKH2}$ and B73.1 (D) but expression of either $\mathrm{NKH}_{A}$ or $\mathrm{NKH} 2$ antigens did not correlate completely with expression of either Leu7 or B73.1. In identical experiments with blood from other normal individuals, coexpression of their antigens in some cells was noted in every instance, but the relative percentages of double 


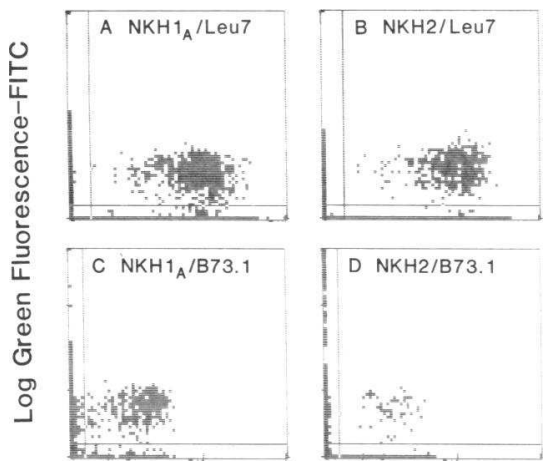

Log Red Fluorescence-PE

Figure 9. Coexpression of $\mathrm{NKH}_{\mathrm{A}}$ and $\mathrm{NKH} 2$ and other NK associated antigens. Cells were analyzed for simultaneous reactivity with directly fluorescein-conjugated monoclonal antibody (either anti$\mathrm{NKH}_{\mathrm{A}}$ or anti-NKH2) and directly phycoerythrin-conjugated antibody (either Leu7 or B73.1/Leu 1 lc) using an Epics V. 10,000 cells were analyzed in each sample. Negative control sample (not shown) was similar to that depicted in Fig. $4 A$ and contained 15 of 10,000 cells that were nonspecifically reactive with both control reagents. As described in the legend to Fig. 4, the two parameter matrix was divided into four quadrants using the lines shown in each graph. Percentages of cells contained within each quadrant were as follows: $A$ : GR $13 \%$, G 6\%, R 12\%, NN 69\%; B: GR 9\%, G 3\%, R $17 \%$, NN $71 \%$; $C$ : GR 7\%, G 15\%, R 29\%, NN 76\%; D: GR 2\%, G 10\%, R 7\%, NN $81 \%$.

positive and single positive cells varied. Since each of these antigens has been associated primarily with cells having the morphology of LGL, these results further indicate the existence of extensive heterogeneity within this relatively small subset of circulating cells.

\section{Discussion}

NK active cells have been defined operationally as a population of cells capable of killing, without apparent preimmunization, allogeneic target cells such as K562 (see reference 27 for review). According to this definition, it has become apparent in both human and murine systems that the population of cells capable of mediating NK activity is very heterogeneous. In human peripheral blood, the diversity of NK cells was suggested by phenotypic analysis of highly purified LGL fractions. Although LGL appear to be morphologically homogeneous and contain virtually the entire pool of NK active PBL, they were found to be very heterogeneous when tested with a series of monoclonal antibodies directed at antigens such as T8, T10, T11, and Mo1 $(4,22)$. One approach to begin to characterize homogeneous populations of NK cells has been to develop stable cloned NK cell lines. Studies on NK clones demonstrated that human cells capable of mediating NK activity displayed distinct phenotypes, and perhaps more importantly, distinct target specificities (5). Moreover, it was shown that at least one subset of NK cells with mature T cell phenotype expressed unique, clonally restricted determinants intimately involved in their cytotoxic function (6). Nevertheless, NK clones are activated NK cells which have been triggered to proliferate following various types of activation stimuli. These clones might therefore represent only one fraction of circulating NK cells, i.e., NK cells that can expand in culture using conditioned medium containing IL-2 (28). Relationships between fresh and cultured NK cells are still unclear, primarily because of a lack of characterization of the various subsets of NK active lymphocytes present in peripheral blood.

To better define the entire population of NK cells and also to identify functionally distinct subsets, we have begun to develop monoclonal antibodies specific for antigens that are selectively expressed on these unique minor cell populations. The strategy we have taken in the present studies is to immunize mice with cloned NK cells and to use these same cells for initial screening of hybridoma supernatants. After identification of hybridomas reactive with the NK clone, antibodies with more selective NK reactivity were readily identified on the basis of lack of reactivity with autologous non-NK cells such as T cell clones and B cell lines. In addition, immunizing NK cloned cells were also used for functional characterization of the reagents as well as biochemical characterization of the target antigens. Using this approach, two monoclonal antibodies, anti-NKH1 $1_{A}$ and anti-NKH2, were chosen for further study because they were specific for two distinct surface antigens that appeared to be selectively associated with cells capable of mediating NK activity.

Anti-NKH1 $1_{A}$ was found to react with $\sim 12 \%$ of circulating lymphocytes and not with any additional hematopoietic cell fraction that was tested. Greater than $90 \%$ of circulating $\mathrm{NKH1}_{\mathrm{A}}+$ cells are large granular lymphocytes. Treatment of PBL with anti-NKH $1_{A}$ plus complement resulted in an almost complete disappearance of NK activity in peripheral blood, although it was found that it was very difficult to destroy LGL displaying lower levels of fluorescence. This observation may explain why there was still a small residual level of NK activity following treatment with anti-NKH1 $1_{\mathrm{A}}$ plus complement. Very importantly, nine NK clones that have been selected on the basis of one unique functional criteria, i.e., the capacity to kill $\mathrm{K} 562$ cells, were all found to express $\mathrm{NKH}_{\mathrm{A}}$ antigen. $\mathrm{NKH}_{1}+$ clones included cells such as JT3 or JT16 which have a common $\mathrm{NK}$ cell phenotype, i.e., T3-T11+ $(4,23$, 24, 29), but in addition, this antigen was found to be present on clones such as JT1 (T3-T11-) and JT9 (T3+T11+), which appear to represent minor populations of NK cells in unstimulated peripheral blood. Biochemical studies indicated that both anti-NKH1 $1_{A}$ and a previously described antibody termed anti-N901 (8) were directed at a molecule which migrates at $\sim 200,000-220,000 \mathrm{~mol} w \mathrm{t}$ in SDS-PAGE analysis. The present data, therefore, confirmed previous results obtained with anti-N901 antibody which demonstrated that virtually the entire NK activity present in human peripheral blood was restricted to the N901+ subset (8). Taken together, these studies strongly suggest that the 200,000 -mol wt molecule can be considered as a pan-NK associated cell surface marker, useful for defining resting as well as activated NK cells. Moreover, the availability of lytic (anti- $\mathrm{NKH}_{\mathrm{A}}$ ) as well as nonlytic (anti-N901) antibodies specific for the same antigen will be useful in designing future studies with these reagents.

Like anti-NKH1 $1_{A}$, anti-NKH2 was shown to display a selective reactivity for LGL. Anti-NKH2 reacted with $\sim 7 \%$ of peripheral blood lymphocytes but monocytes, granulocytes, red cells, platelets, PHA-activated E+ cells, thymocytes, and a series of 14 in vitro established cell lines were found to be negative. While NKH2 + cells could not be readily distinguished morphologically from $\mathrm{NKH}_{\mathrm{A}}$ cells, both complement lysis and two color immunofluorescence studies demonstrated that 
distinct subsets of LGL can be either $\mathrm{NKH}_{\mathrm{A}}+, \mathrm{NKH} 2+$, $\mathrm{NKH}_{\mathrm{A}}+, \mathrm{NKH} 2-$, or $\mathrm{NKH}_{\mathrm{A}}=, \mathrm{NKH} 2+$. More importantly, the subsets defined by these antigens were found to be functionally distinct. As opposed to results obtained with anti$\mathrm{NKH1}_{\mathrm{A}}$, treatment of PBMC with anti-NKH2 plus complement did not significantly alter NK activity in peripheral blood. Moreover, when LGL enriched fractions were sorted into $\mathrm{NKH} 2+$ and NKH2 - subpopulations it was shown that high NK activity was still found in the negative fraction, and $\mathrm{NKH} 2+$ cells displayed very little NK activity.

In accordance with the studies of unstimulated peripheral blood, phenotypic characterization of a series of NK clones confirmed that both $\mathrm{NKH}_{\mathrm{A}}$ and $\mathrm{NKH} 2$ antigens could be coexpressed at the single cell level. Out of nine NK clones which were all $\mathrm{NKH}_{\mathrm{A}}+$, four were found to coexpress $\mathrm{NKH} 2$. This clonal analysis indicated that $\mathrm{NKH}_{\mathrm{A}}$ and $\mathrm{NKH} 2$ were coexpressed on individual cells such as JT3 or JT16, which have a common NK cell phenotype (T11+T3-N901+). In addition, these experiments showed that $\mathrm{NKH} 2$ was present on diverse clones such as JT1 (T11-T3-) and $\mathrm{JT}_{\mathrm{A}} 17$ $(\mathrm{T} 3+\mathrm{T} 11+)$, suggesting that this antigen can be found on widely different subpopulations of NK active lymphocytes. These results are also consistent with the finding that subsets of both $\mathrm{NKH}_{\mathrm{A}}$ and $\mathrm{NKH} 2$ positive cells coexpressed $\mathrm{T} 3$ as well as T11 antigen.

In five out of six experiments, resting sorted $\mathrm{NKH} 2+$ cells displayed low NK activity, whereas clones expressing NKH2 were strongly cytotoxic. This apparent discrepancy cannot be explained by a blocking effect of the antibody on NKH2+ sorted cells, since anti-NKH2 was unable to alter cytotoxic function of NKH2+ clones. Rather, it may well relate to the fact that the NK clones represent activated cells and each clone was selected specifically on the basis of its cytotoxic activity. In contrast to NK clones, peripheral blood LGL are, in their great majority, resting cells which do not express activation antigens such as T9 or Ia, and which do not divide spontaneously in culture $(4,22)$. NKH2+ clones displaying strong NK activity may therefore represent a counterpart of a fraction of NKH2 + circulating LGL which require activation signals (such as interferon or IL-2) to display a fully effective cytotoxicity. If this hypothesis were correct, these $\mathrm{NKH} 2+$ LGL could function as a pool of "pre-NK cells" that would be able to be recruited during an immune response. Alternatively, cells such as JT1, JT3, JT15, and $\mathrm{JT}_{\mathrm{A}} 17$ may simply represent minor populations of $\mathrm{NKH1}_{\mathrm{A}}+\mathrm{NKH} 2+$ LGL displaying strong cytotoxicity in resting peripheral blood. In either case, the present results demonstrate that expression of NKH2 delineates a subset of LGL that is functionally distinct from the subset defined by anti-NKH1 $1_{\mathrm{A}}$. Further studies will have to be carried out to establish the relationship which exists between NKH2+ LGL and resting as well as activated NK cells.

It was found that anti-NKH2 precipitated a structure of $60,000 \mathrm{~mol}$ wt in SDS-PAGE analysis under reducing conditions. This molecular weight is similar to that of B73.1 antigen, which has been shown to function as an Fc receptor structure $(16,17)$. B73.1 and NKH2 are clearly distinct, however, since the former is expressed on granulocytes as well as LGL. Simultaneous two color immunofluorescence also demonstrated that only a small fraction of cells in peripheral blood coexpresses both antigens, and that most $\mathrm{NKH} 2+$ cells in peripheral blood are B73.1 - and vice versa. In addition, $\mathrm{NKH2}$, as opposed to
B73.1, does not appear to be directly involved in ADCC because anti-NKH2 does not block antibody dependent cytotoxicity mediated by JT3 cells (data not shown) and clones such as JT9, JT10, JT11, $\mathrm{JT}_{\mathrm{B}} 18$, which are very strongly lytic in ADCC assays (unpublished data), are NKH2-. Nevertheless, the similarity of molecular weight between B73.1 and NKH2 might still suggest that these two NK-associated antigens belong to the same family of molecules.

In summary, the present studies suggest that anti-NKH1 ${ }_{\mathrm{A}}$ and anti-NKH2 are capable of dissecting populations of LGL into distinct functional subsets with varying levels of NK activity. Using these two antibodies, LGL can be divided into three populations: $\mathrm{NKH}_{\mathrm{A}}+, \mathrm{NKH} 2+; \mathrm{NKH}_{\mathrm{A}}+, \mathrm{NKH} 2+$; and $\mathrm{NKH}_{\mathrm{A}}+, \mathrm{NKH} 2-$. Since $\mathrm{NKH} 2+$ cells were found to display low NK activity in the resting state, the latter subset appears to contain the most strongly cytotoxic cells in peripheral blood of most normal individuals. LGL in the first subset that express both $\mathrm{NKH}_{\mathrm{A}}$ and $\mathrm{NKH} 2$ antigens can display strong cytotoxicity when activated, such as in cultured NK clones, but the functional activity of these cells in unstimulated peripheral blood has not yet been determined. Finally, the function of LGL that express NKH2 antigen only has not been evaluated in this study, but no NK clones representing this phenotype have yet been found, and there is no evidence to indicate that these cells have significant NK activity in peripheral blood. Further studies utilizing dual immunofluorescence markers will be able to purify these different fractions and characterize their respective function in a resting state as well as following activation. Hopefully, the identification of this series of NKassociated antigens will lead to a better understanding of the diversity of NK cells, and ultimately help to clarify both their lineage derivation and biological significance.

\section{Acknowledgments}

Dr. Schmidt is a recipient of a fellowship (Schm 596/1-1) from the Deutsche Forschungsgemeinschaft. This work was supported by National Institutes of Health grants CA 19589 and CA 34183.

\section{References}

1. Lust, J. A., V. Kumar, R. C. Burton, S. P. Bartlett, and M. Bennett. 1981. Heterogeneity of natural killer cells in the mouse. $J$. Exp. Med. 154:306-317.

2. Minato, N., L. Reo, and B. R. Bloom. 1981. On the heterogeneity of murine natural killers. J. Exp. Med. 154:750-762.

3. Zarling, J. M., K. A. Crouse, W. E. Biddison, and P. C. Kung. 1981. Phenotypes of human natural killer cell populations detected with monoclonal antibodies. J. Immunol. 127:2575-2580.

4. Hercend, T., S. C. Meuer, E. L. Reinherz, S. F. Schlossman, and J. Ritz. 1982. Generation of a cloned NK cell line derived from the "null cell" fraction of human peripheral blood. J. Immunol. 129: 1299-1305.

5. Hercend, T., E. L. Reinherz, S. C. Meuer, S. F. Schlossman, and J. Ritz. 1983. Phenotypic and functional heterogeneity of human cloned natural killer cell lines. Nature (Lond.). 301:158-160.

6. Hercend, T., S. C. Meuer, A. Brennan, M. A. Edson, O. Acuto, E. L. Reinherz, S. F. Schlossman, and J. Ritz. 1983. Identification of a clonally restricted $90 \mathrm{KD}$ heterodimer on two human cloned natural killer cell lines: its role in cytotoxic effector function. J. Exp. Med. 158:1547-1560.

7. Kohler, G., and C. Milstein. 1975. Continuous culture of fused cells secreting antibodies of predefined specificity. Nature (Lond.). 256: 495-497. 
8. Griffin, J. D., T. Hercend, R. P. Beveridge, and S. F. Schlossman. 1983. Characterization of an antigen expressed by human natural killer cells. J. Immunol. 130:2947-2951.

9. Reinherz, E. L., P. C. Kung, G. Goldstein, and S. F. Schlossman. 1979. A monoclonal antibody with selective reactivity with functionally mature human thymocytes and all peripheral human $\mathrm{T}$ cells. $J$. Immunol. 123:1312-1317.

10. Reinherz, E. L., P. C. Kung, G. Goldstein, and S. F. Schlossman. 1980. A monoclonal antibody reactive with the human cytotoxic/ suppressor $\mathrm{T}$ cell subset previously defined by a heteroantiserum termed $\mathrm{TH}_{2}$. J. Immunol. 124:1301-1307.

11. Reinherz, E. L., P. C. Kung, G. Goldstein, and S. F. Schlossman. 1979. Separation of functional subsets of human T cells by a monoclonal antibody. Proc. Natl. Acad. Sci. USA. 76:4061-4065.

12. Reinherz, E. L., S. C. Meuer, K. A. Fitzgerald, R. E. Hussey, H. Levine, and S. F. Schlossman. 1982. Antigen recognition by human $\mathrm{T}$ lymphocytes is linked to surface expression of the T3 molecular complex. Cell. 30:735-743.

13. Nadler, L. M., P. Stashenko, R. Hardy, J. M. Pesando, E. J. Yunis, and S. F. Schlossman. 1981. Monoclonal antibodies defining serologically distinct HLA-D/DR related Ia-like antigens in man. Hum. Immunol. 1:77-90.

14. Todd, R. F., III, L. M. Nadler, and S. F. Schlossman. 1981. Antigens on human monocytes identified by monoclonal antibodies. J. Immunol. 120:1435-1442.

15. Abo, T., and C. M. Balch. 1981. A differentiation antigen of human NK and $\mathrm{K}$ cells identified by a monoclonal antibody (HNK1). J. Immunol. 127:1024-1029.

16. Perussia, B., S. Starr, S. Abraham, V. Fanning, and G. Trinchieri. 1983. Human natural killer cells analyzed by B73.1, a monoclonal antibody blocking receptor functions. I. Characterization of the lymphocyte subset reactive with B73.1. J. Immunol. 130:21332141.

17. Perussia, B., O. Acuto, C. Terhorst, J. Faust, R. Lazarus, V. Fanning, and G. Trinchieri. 1983. Human natural killer cells analyzed by B73.1, a monoclonal antibody blocking Fc receptor functions. II. Studies of B73.1 antibody-antigen interaction on the lymphocyte membrane. J. Immunol. 130:2142-2148.

18. Griffin, J. D., R. P. Beveridge, and S. F. Schlossman. 1982. Isolation of myeloid progenitor cells from peripheral blood of chronic myelogenous leukemia patients. Blood. 60:30-37.
19. van Agthoven, A., C. Terhorst, E. L. Reinherz, and S. F. Schlossman. 1981. Characterization of T cell surface glycoproteins $\mathrm{T} 1$ and $\mathrm{T} 3$ present on all mature $\mathrm{T}$ lymphocytes and functionally mature thymocytes. Eur. J. Immunol. 11:18-21.

20. Bonner, W. M., and R. A. Laskey. 1974. A film detection method for tritium-labelled proteins and nucleic acids in polyacrylamide gels. Eur. J. Biochem. 46:83-88.

21. Timonen, T., J. R. Ortaldo, and R. B. Herberman. 1981. Characteristics of human large granular lymphocytes and relationship to natural killer and K cells. J. Exp. Med. 153:569-582.

22. Ortaldo, J. R., S. L. Sharrow, T. Timonen, and R. B. Herberman. 1981. Determination of surface antigens on highly purified human NK cells by flow cytometry with monoclonal antibodies. J. Immunol. 127 2401-2409.

23. Abo, T., M. D. Cooper, and C. M. Balch. 1983. Characterization of HNK1+ (Leu7) human lymphocytes. I. Two distinct phenotypes of human NK cells with different cytotoxic capability. J. Immunol. 129: 1752-1757.

24. Lanier, L. L., A. M. Le, J. H. Phillips, N. L. Warner, and G. F. Babcock. 1983. Subpopulations of human natural killer cells defined by expression of the Leu7 (HNK1+) and Leull (NK15) antigens. J. Immunol. 129:1789-1796.

25. Phillips, J. J., and G. F. Babcock. 1983. NKP-15: a monoclonal antibody reactive against purified human natural killer cells and granulocytes. Immunol. Lett. 6:143.

26. Rumpold, H., D. Kraft, G. Obexer, G. Bock, and W. Gebhart. 1982. A monoclonal antibody against a surface antigen shared by human large granular lymphocytes and granulocytes. J. Immunol. 129: 1458-1464.

27. Trinchieri, G., and B. Perussia. 1984. Human natural killer cells: biologic and pathologic aspects. Lab. Invest. 50:489-513.

28. Abo, T., C. A. Miller, C. M. Balch, and M. D. Cooper. 1983. Interleukin 2 receptor expression by activated HNK1+ granular lymphocytes: a requirement for their proliferation. J. Immunol. 131:18221826.

29. Breard, J., E. L. Reinherz, C. O'Brien, and S. F. Schlossman. 1980. Delineation of an effector population responsible for natural killing and antibody-dependent cellular cytotoxicity. Clin. Immunol. Immunopathol. 18:145-150. 